\title{
Correction to: Threats of Climate Change in Small Oceanic Islands: The Case of Climate and Agriculture in the Galapagos Islands, Ecuador
}

Carlos F. Mena, Homero A. Paltán, Fatima L. Benitez, Carolina Sampedro, and Marilú Valverde

\section{Correction to:}

Chapter 5 in: S. J. Walsh et al. (eds.), Land Cover and Land Use Change on Islands, Social and Ecological Interactions in the Galapagos Islands, https://doi.org/10.1007/978-3-030-43973-6_5

The original version of this chapter was revised due to author name was incorrectly mentioned. This has now been updated as "Homero A. Paltán" in the chapter opening page and front matter of the book. 